\title{
Editorial
}

Nephrology

Published online: November 17, 2015

DOI: $10.1159 / 000441628$

\section{Antioxidants Therapy for Patients with Chronic Kidney Disease: A Question of Balance}

\author{
Jing Chen Ravi Siriki
}

Division of Nephrology and Hypertension, Department of Medicine, Tulane University School of Medicine, New Orleans, La., USA

Oxidative stress reflects an imbalance between an excessive generation of oxidant compounds and reduced antioxidant defenses. Findings from prospective cohort studies suggest a possible etiopathogenetic role of oxidative stress in cardiovascular disease (CVD) among patients with coronary artery disease and chronic kidney disease (CKD) $[1,2]$, while clinical trials using antioxidants failed to demonstrate beneficial effect in patients with increased CVD risk and CKD $[3,4]$. The discrepancy observed in these findings warrants explanation. Oxidative stress levels are increased in patients with CKD due to increased production and decreased renal clearance of reactive oxygen species, as well as a dysfunctional antioxidant defense system $[5,6]$. This increased production and reduced antioxidant defense capability may be due to multiple etiologies, including traditional CVD risk factors and inflammation [7]. Therefore, treatment for reducing oxidative stress in CKD patients should target multiple levels. We and others propose 4 major challenges in antioxidant therapy for CKD patients: (1) the optimal control of the etiology may not be easily achieved; therefore, oxidative stress can regenerate during antioxidant therapy; (2) the optimal dose of antioxidants for targeting specific levels of oxidative stress remains to be fully evaluated; (3) in the presence of high oxidative stress, many antioxidants can be oxidized to pro-oxidative substances that can cause oxidative stress; therefore, the choice of antioxidant may affect the success of the treatment; and (4) the efficacy of a combination of antioxidants acting at multiple levels of the antioxidant system is unknown. It is plausible that combination therapy targeting multiple levels may be more effective.

In this issue of the American Journal of Nephrology, Ilori et al. [8] reported the association of oxidative balance score (OBS) and CKD among 19,461 participants in the Reasons for Geographic and Racial Differences in Stroke Study with a median follow-up of 3.5 years. The OBS was calculated by combining 13 a priori-defined pro-oxidants and antioxidants by using a baseline dietary and lifestyle assessment. Diet, medications, and lifestyle are major exogenous sources of both antioxidants and pro-oxidants [9]. The study findings suggested that a higher OBS (which is reflective of higher antioxidant levels) was associated with a lower prevalence of CKD. However, there was no significant association between OBS and end-stage renal disease (ESRD) incidence in the multivariable analyses, which may be due to an insufficiency of statistical power, given the small number of incident ESRD cases. The OBS has also been shown to correlate inversely with all-cause mortality in other popula-

\section{KARGER 125}

(c) 2015 S. Karger AG, Base

0250-8095/15/0424-0318\$39.50/0
Jing Chen, MD, MSc

Department of Medicine

Tulane University School of Medicine

1430 Tulane Ave., SL-45, New Orleans, LA 70112 (USA)

E-Mail jchen@tulane.edu 
tions [10]. These findings suggest the potential usefulness of an integrated approach to evaluate the balance between exogenous oxidants and antioxidants in CKD risk evaluation and prediction. In addition, antioxidant supplements might provide kidney protection. Furthermore, an evaluation of exogenous oxidants in guiding antioxidant therapy may be valuable for individualized care in CKD patients. Finally, controlling and modifying exogenous oxidants via diet and lifestyle modification in individuals with reduced kidney clearance would be a promising approach, especially when combined with antioxidant therapy. Further studies in these important areas are warranted.

\section{Disclosure Statement}

We have no conflict of interest to declare.

\section{References}

1 Walter MF, Jacob RF, Bjork RE, Jeffers B, Buch J, Mizuno Y, Mason RP: Circulating lipid hydroperoxides predict cardiovascular events in patients with stable coronary artery disease: the PREVENT study. J Am Coll Cardiol 2008;51:1196-1202.

2 Shoji T, Fukumoto M, Kimoto E, Shinohara K, Emoto M, Tahara H, Koyama $\mathrm{H}$, Ishimura E, Nakatani T, Miki T, Tsujimoto Y, Tabata T, Nishizawa Y: Antibody to oxidized low-density lipoprotein and cardiovascular mortality in end-stage renal disease. Kidney Int 2002;62: 2230-2237.

3 Cook NR, Albert CM, Gaziano JM, Zaharris E, MacFadyen J, Danielson E, Buring JE, Manson JE: A randomized factorial trial of vitamins $\mathrm{C}$ and $\mathrm{E}$ and beta carotene in the secondary prevention of cardiovascular events in women: results from the Women's Antioxidant Cardiovascular Study. Arch Intern Med 2007;167:1610-1618.

4 Himmelfarb J, Ikizler TA, Ellis C, Wu P, Shintani A, Dalal S, Kaplan M, Chonchol M, Hakim RM: Provision of antioxidant therapy in hemodialysis (PATH): a randomized clinical trial. J Am Soc Nephrol 2014;25:623-633.

5 Massy ZA, Stenvinkel P, Drueke TB: The role of oxidative stress in chronic kidney disease. Semin Dial 2009;22:405-408.

6 Rebholz CM, Wu T, Hamm LL, Arora R, Khan IE, Liu Y, Chen CS, Mills KT, Rogers S, Kleinpeter MA, Simon EE, Chen J: The association of plasma fluorescent oxidation products and chronic kidney disease: a casecontrol study. Am J Nephrol 2012;36:297304.
7 Galle J, Quaschning T, Seibold S, Wanner C: Endothelial dysfunction and inflammation: what is the link? Kidney Int Suppl 2003; 63:S45-S49.

8 Ilori TO, RO YS, Kong SY, Gutierrez RM, Ojo AO, Judd AE, Narayan KM, Goodman M, Plantinga L, McClellan W: Oxidative balance score and chronic kidney disease. Am J Nephrol 2015;42:320-327.

9 Goodman M, Bostick RM, Dash C, Flanders WD, Mandel JS: Hypothesis: oxidative stress score as a combined measure of pro-oxidant and antioxidant exposures. Ann Epidemiol 2007;17:394-399.

10 Van Hoydonck PG, Temme EH, Schouten EG: A dietary oxidative balance score of vita$\min \mathrm{C}$, beta-carotene and iron intakes and mortality risk in male smoking Belgians. J Nutr 2002;132:756-761. 